\title{
Design and Implementation of UAV Architecture for Delivering Medical Products
}

\author{
K. Nagasivaranjani, V. Muthu Kavitha, V. Divya Prabha, C. Asha Beaula
}

\begin{abstract}
Unmanned Aerial vehicles (UAVs) likewise regularly alluded to as automatons, and are increasing incredible research intrigue, consideration as a significant future innovation. These vehicles have almost boundless potential essentially because of their high mobility and small scale size, that permits their utilization in different applications. Among numerous kinds of UAVs, the multi-copter UAVs with 4 rotors (quadcopter) are being utilized and used regularly. Automatons are semi-self-governing airplanes that can be controlled and worked remotely. Economically accessible automatons are progressively being utilized in an assortment of uses. It is being used in a variety of applications such as,3-D mapping, disaster monitoring, aerial packet delivery, photography and filming, and very useful in the field of monitoring and surveillance also in unmanned cargo system .Recent innovations made huge growth in this field that made the researchers to develop applications which are useful in the field of medicine to deliver drugs, blood products in remote areas. A medical drugs is delivered to the person based on the location which was identified through GPS module.This system offers the medicine to be delivered to the right person and at right time.
\end{abstract}

Key Words: UAV Unmanned Aerial Vehicle, GPS Global Positioning System ,DC Direct Current, ESC Electronic Speed Controller, LCD Liquid Crystal Display, APM Arduo Pilot Mega, DSSS Direct Sequence Spread Spectrum, FHSS Frequency Hopping Spread Spectrum, PWM Pulse Width Modulation.

\section{INTRODUCTION}

An unmanned aerial vehicle is an airplane without an individual's pilot locally available and a sort of unmanned vehicle. UAVs are a part of an unmanned airplane framework arrangement of correspondences [1]. UAVs flight are worked by assortment of methods they can be worked self-rule either

Revised Manuscript Received on February 05, 2020.

* Correspondence Author

K. Nagasivaranjani, Department of Electronics and Communication Engineering, National Engineering College, kovilpatti, India.

E-mail:ranjanikarthik98@gmail.com

V. Muthu Kavitha, Department of Electronics and Communication Engineering, National Engineering College, kovilpatti, India.

E-mail:muthukavitha398@gmail.com

V. Divya Prabha, Department of Electronics and Communication Engineering, National Engineering College, kovilpatti, India.

C. Asha Beaula, Department of Electronics and Communication Engineering, National Engineering, college, Kovilpatti., Tamil Nadu, India. E-mail: ashajulus.nec@gmail.com

(C) The Authors. Published by Blue Eyes Intelligence Engineering and Sciences Publication (BEIESP). This is an open access article under the CC BY-NC-ND license (http://creativecommons.org/licenses/by-nc-nd/4.0/) which incorporates a UAV, a ground-based controller, and an

E-mail: divyaprabha507@gmail.com

under remote by an installed PCs or by individual's administrator or self-governingly without labor

Contrasted with maintained airplane, UAVs were regularly utilized for missions. At the point when they are begun they were for the most part utilized in military applications, however now their utilization is quickly extending to logical and recreational exercises which incorporate item conveyances, elevated photography, policing and surveillance[3]. Different applications incorporate recreational, carrying, rural, business, droneracing, Components like correspondence framework stations, information joins, and other help types of gear are utilized by Military UAV framework and they are utilized by military organizers to assign the different individual airplane components in a general use plan. The fundamental exemptions are the cockpit and ecological framework or life emotionally supportive networks. A few automatons have payloads which weigh not exactly a human grown-up, and subsequently, can be viewed as little. Weaponized military UAVs are lighter than their ran partners with practically identical combat hardware eventhough they convey overwhelming payloads. Little UAVs which are utilized for non military personnel applications are worked out utilizing less materials and shapes, that can utilize less powerfully tried electronic control frameworks. For little UAVs, the quadcopter configuration has gotten well known, however this format is never utilized for maintained airplane. Little electric engines and batteries control frameworks for UAVs are regularly not quite the same as that of manned art which use Scaling down method that has less drive innovation that aren't doable for maintained airplane .

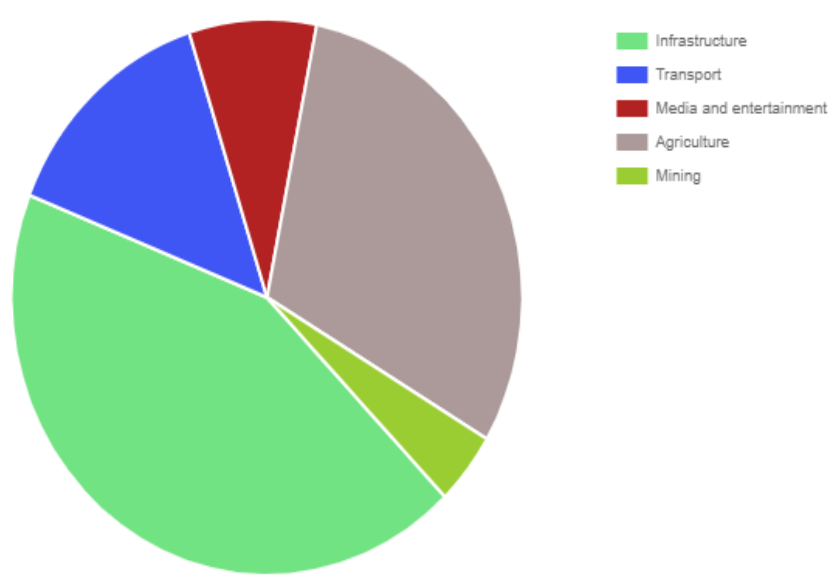

Fig 1.1.contribution of UAV in different key industries

Published By:

Blue Eyes Intelligence Engineering 


\begin{tabular}{|l|l|l|}
\hline Infrastructure & 43 \\
\hline Transport & 14 \\
\hline Media and entertainmel & 8 \\
\hline Agriculture & 30.2 \\
\hline Mining & 4.2 \\
\hline
\end{tabular}

Fig 1.2. Predicted values of UAV usage

Figure 1.2 it is clear that UAV has wide application in major key industries. The usage of unmanned aerial vehicles (UAVs) in civilian domains are growing tremendously in all aspects of technology. As they include applications like remote sensing, wireless coverage and they are helpful in providing realtime monitoring, security and surveillance delivery of goods in aerial areas and very helpful in the search and rescue operations, precision of agriculture, and civil infrastructure inspection play a major role. Reduced risks and providing lower cost are the major reason why they are especially used . Decreased dangers and giving lower cost are the significant motivation behind why they are particularly utilized in common framework .Shrewd UAVs are the following huge upheaval in UAV innovation promising to give new open doors in various applications.

\section{PICTORIAL REPRESENTATION OF UAV}

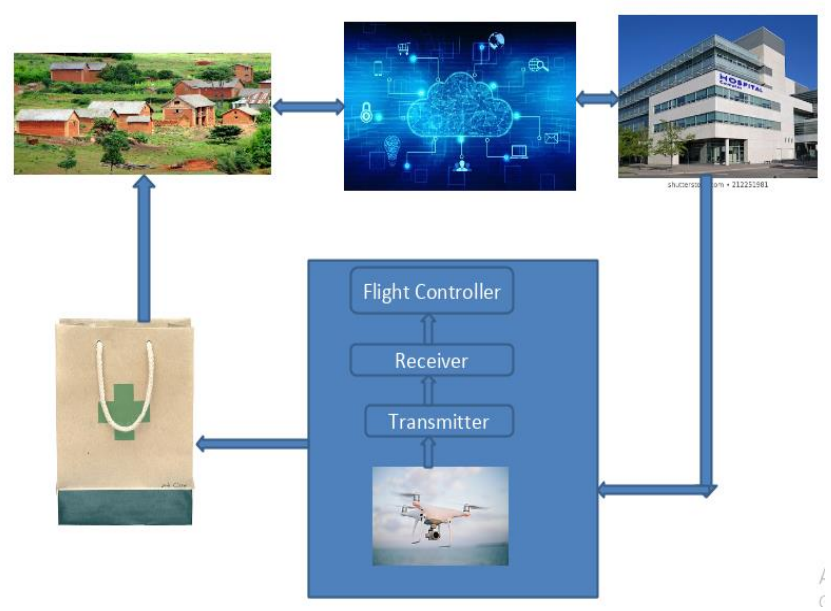

Fig 2.1. Block diagram of UAV in medical delivery

The main objective was to deliver the medical drugs to the persons where the population is high and traffic was main constraint. Drugs required by the peoples in rural areas are inserted to the drone. Drone receiver receives commands and instruction from the transmitter which works at $2.4 \mathrm{GHZ}$ which consists of APM flight controller. The automaton is then explored to the country territories by an administrator until it finds a workable pace region.After effectively landing at the district the automaton is again explored back to a similar spot.

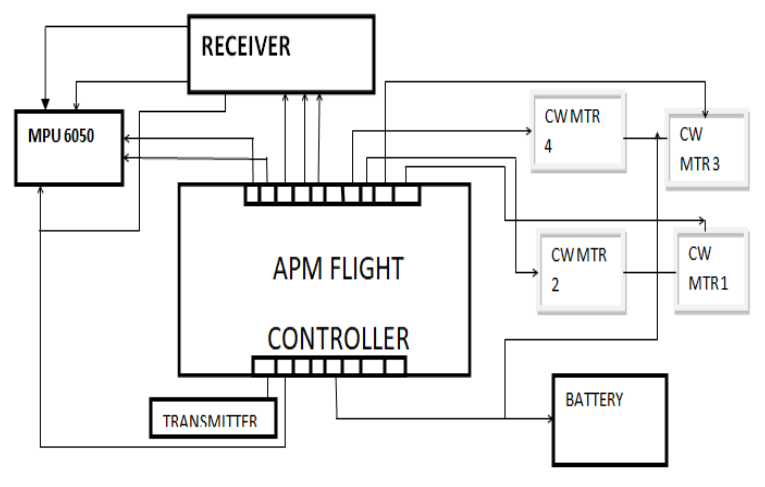

Fig2.2 Architecture of UAV

The Collector is associated with APM flight controller Kk2.1.5 Multi-rotor LCD control board With 6050mpu And Atmel 644PA is that ensuing enormous advancement of the original KK control loads up.

Receiver (R9DS)receives the signal and commands and it's further connected to the APM flight controller which contains accelerometer and gyroscope for determining an orientation and linear acceleration supported vibration. Four Brushless Motor which rotates at the speed of $32,760 \mathrm{rpm}$ without propellers and its efficiency is about 85-90\%which is typically greater than a typical DC motor. As brushless motors are used, this drone can hold more weighed medicines as compared to plain drones.

\section{COMPONENTS USED IN ARCHITECTURE}

\section{A . BRUSHLESS MOTOR}

UAV uses a motor named Brushless motors which do not have brushes .A brushless motor is an electronically commutated DC motor.The speed and torque of the electric motor was controlled by providing pulses from the controller to the motor windings.So these kind of motors are highly efficient in producing large amount of torque with huge speed range. Permanent magnets rotate around a hard and fast armature in brushless motors which is not present in brushed motors this help us to achieve large efficiency when compared to conventional brushed motors.

\section{B. ELECTRONIC SPEED CONTROLLER}

The term ESC is abbreviated as electronic speed control is an electronic circuit used to control and change the speed of an electric motor which was connected to them. It also helps in finding its route and also to perform as a dynamic brake. ESC are often used in the radio controlled models which are powered electrically,the changes are usual for brushless motors it provides an electronically produced 3 phase electrical power which have low voltage source and it is given to the motor which was connected to ESC

Published By:

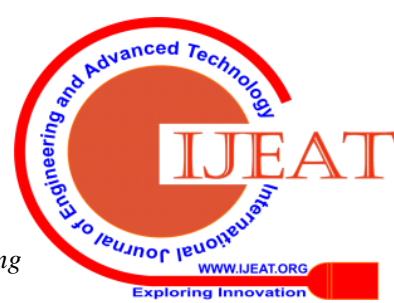




\section{KK 2.1.5 MULTI-ROTOR LED FLIGHT CONTROLLER}

The KK2.1.5 Multi-Rotor controller is a flight controller board used for the construction of multi-rotor aircraft and other civilian applications. The Atmega 644PA IC is employed to process the signals consistent with the users by selecting the firmware after the selection was completed the processed signals and control signals are passed to the installed Electronic Speed Controllers (ESCs).

\section{D.TRANSMITTER}

Transmitter used in the drone is Fly Sky Remote have programming functionality that can be configured according to our needs which allows for custom mixing and adjusting of the channels.Fly sky transmitter is used to control quadcopter which operates under the frequency of $2.4 \mathrm{GHZ}$.

\section{E. RECEIVER}

Radiolink R9DS, which works under the recurrence the 2.4GHZ, which has 10 directs collector in it. DSSS and FHSS spread range working synchronously and they are utilized for Radiolink transmitters. This beneficiary gets directions and guidance from the transmitter and send the data.This receiver receives commands and instruction from the transmitter and send the information .

\section{F. LITHIUM BATTERY}

A lithium-ion battery isotherwise known as Li-ion battery is a kind of rechargeable battery. Lithium-ion batteries are used commonly in all portable electronics and electric appliances and nowadays it is widely used for military and aerospace applications.

\section{G. GPS MODULE}

GPS module helps in identifying the current position of the drone.The main purpose of the GPS satellites is to transmit information and data back to earth over radio frequency (ranging from 1.1 to $1.5 \mathrm{GHz}$ ).With this available information and some mathematical calculation which uses a ground based receiver or GPS module that enables the user to get accurate position and time.

\section{H. NODE MCU}

NODE MCU is the Development board with ESP8266 module .NODE MCU costs low stand alone wireless transceiver which can be used for end-point IOT developments .Node MCU Development board is available with wifi capability, they are also provided with analog pin, digital pins and serial communication protocols.

\section{PROPOSED MODEL}

Flysky CT6B is a 6 channel radio transmitter works in the frequency of $2.4 \mathrm{GHZ}$ which is ideal for quadcopters and muliticopter that sends signals and commands to the receiver. Receiver is connected to kk 2.1.5 multi-rotor controller which was a flight control board for multi-rotor aircrafts and other applications.

Function of the multirotor is to stabilize the aircraft and its purpose is to take the signal from $6050 \mathrm{MPU}$ and passes the signal to Atmega 644PA IC which process these signals According to the user need it passes the control signal and messages to the Electronic speed Controller(ESC) installed in
it.These signals instruct the ESCs to make fine adjustments to the motor so that the rotational speed is controlled which inturn stabilizes the multi-rotor.ESCs are connected to Four Brushless Motor which rotates at the rate of $32,760 \mathrm{rpm}$ without propellers and its efficiency is about $85-90 \%$ which is typically greater than conventional DC motors. As shown in fig 5 brushless motors are used ,this drone can hold more weighed medicines as compared to conventional drones.

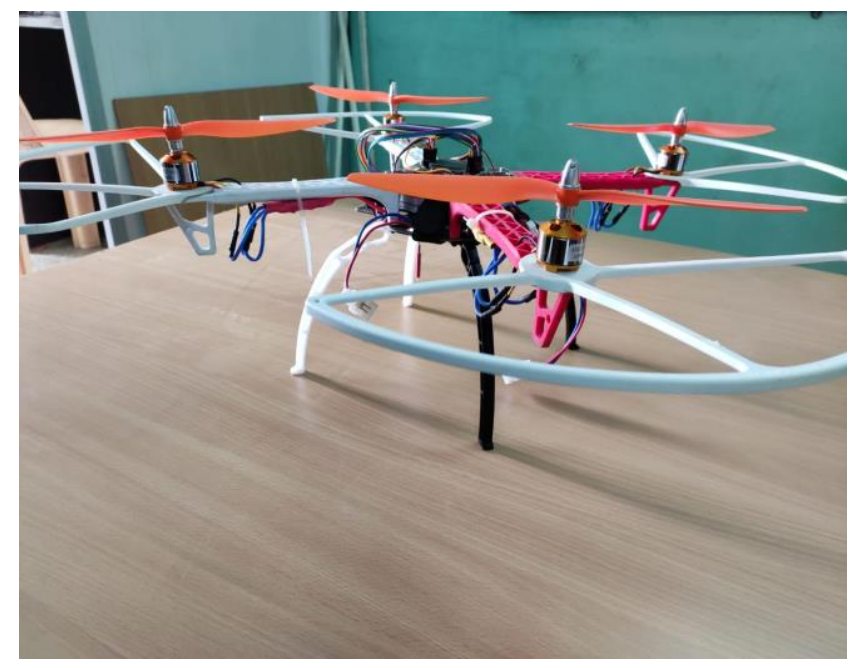

Fig 4.1. Side view of brushless motor

Figure 4.1 shows top view of UAV which carries medicinal products .Brushless motor have highest rpm which helps in the safer and faster delivery of drugs.

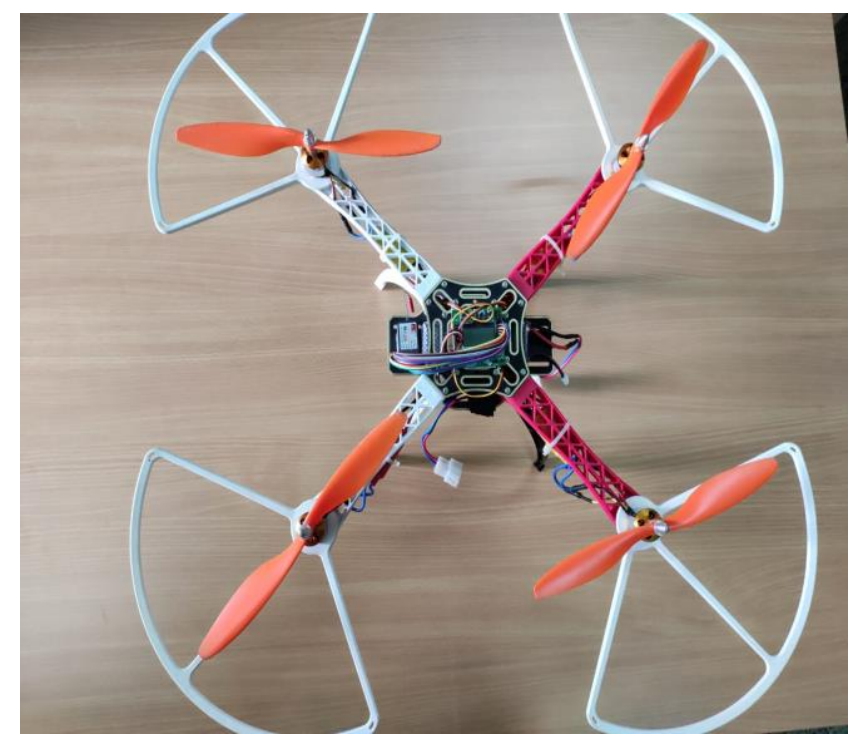

Fig 4.2.Top view of UAV

\section{V.RESULT AND DISCUSSION}

Rapid resource depletion because of exponential population increase results in poor drugs delivery and medical products to the places and other affected areas [5]. Places which suffers from traffic problem failed to transport the important products in correct time. The proposed product rectified the problems.

Published By:

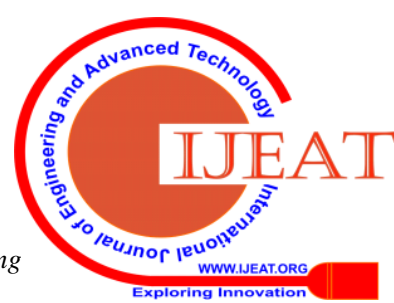




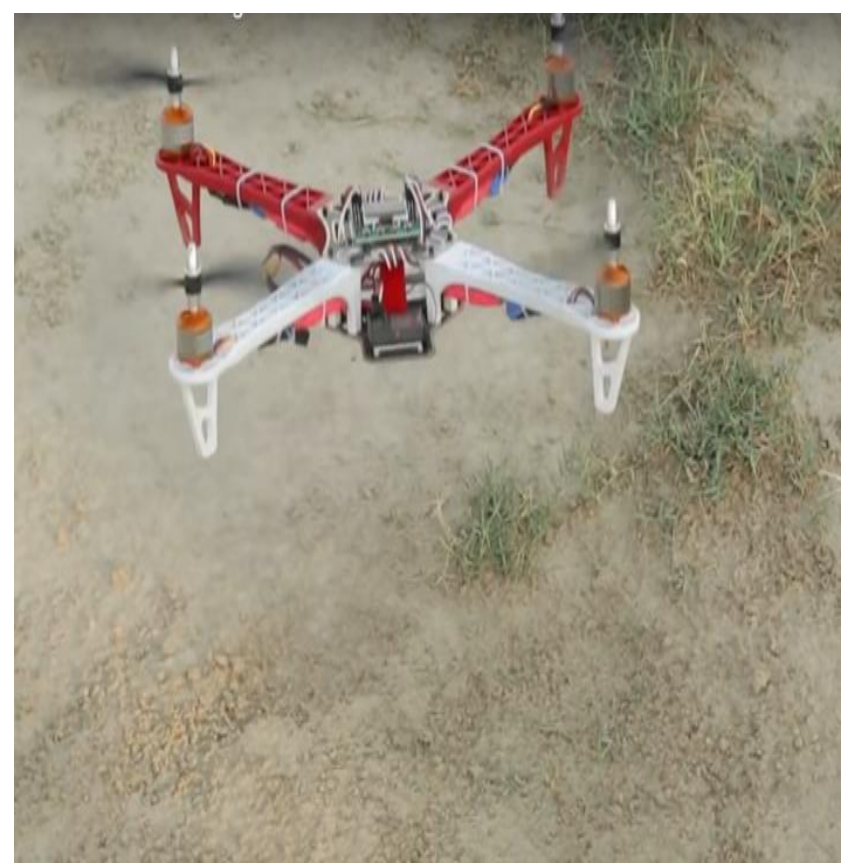

Fig 5.1Aerial view of UAV

Unmanned airborne vehicles (UAV) which have the great ability to move products securely, rapidly and economically across both available and difficult to reach to people was structured. Goal of this undertaking is to exhibit the practicality of utilizing ramble( UAVs) to move pharmaceutical items to country districts .The prescriptions required by the individuals in provincial zones are stacked on the automaton. The automaton is then sent to the rustic regions by an administrator until it finds a good pace goal. After effectively landing to the specific locale the automaton lands at a particular area where the genuine client who requested the medication was pausing. The beneficiary recovers the medications from the drone[7]. After the fruitful conveyance of the drugs to the proposed beneficiary in the rustic locale it returns back to a similar spot.

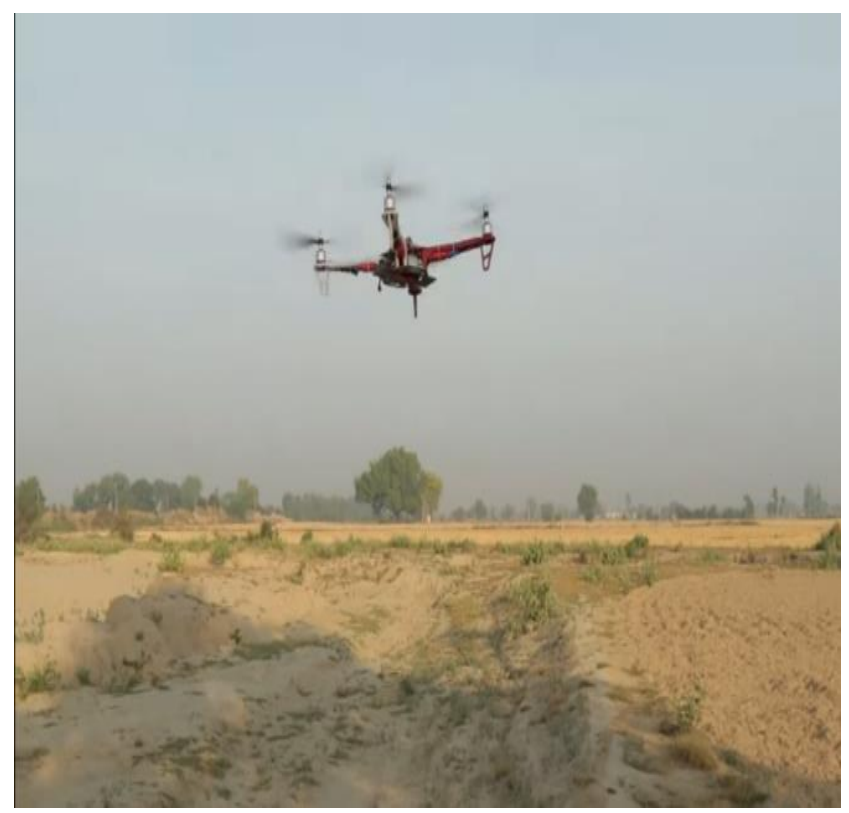

Fig 5.2 UAV during take off

\section{A. DISTANCE COVERED BY DRONE}

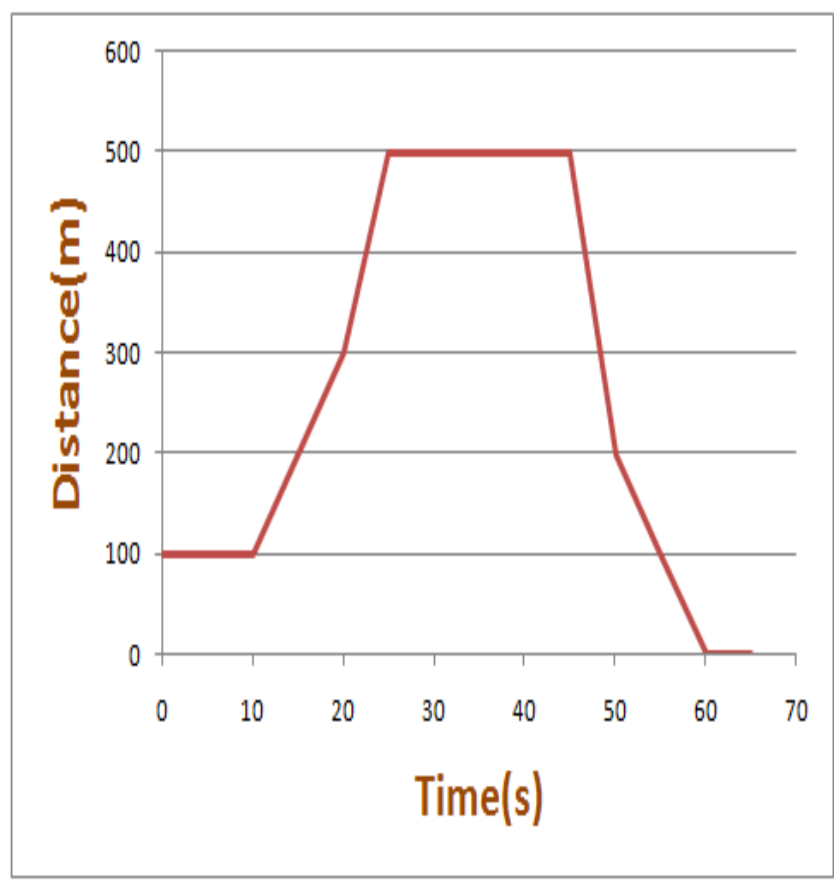

Fig 5.3.Distance vs time graph

This graph was plotted against time and distance .Drone which has the capacity to travel through accessible and unaccessible area will cover a distance of $500 \mathrm{~m}$ in 60 s which enables us faster and safer transport of medical goods[14].

\section{METHODOLOGY USED IN DELIVERY OF MEDICINE THROUGH UAV}

UAV carry medicines are deployed with GPS module .GPS module used here is neo 650 which enables the user to find the exact location of drone. In addition to GPS module drone also carries NODE MCU with ESP8266 module which has wifi module within it.

\section{A.WEB PAGE CREATION}

A webpage contains lines of code written in HTML language which can be read by any browser. This webpage is created by the user, URL of the webpage gets communicated with the drone as the drone contains ESP8266 module within it. Information of the user accessing the webpage will be stored in database . Database is a container where we can place data.Databae consists of tables,rows and columns within it. Php is a server side language which understands html and php also interact with MySQL database. Thus the webpage was created by above methodologies, which enables the user to receive their medicines whenever they need. 


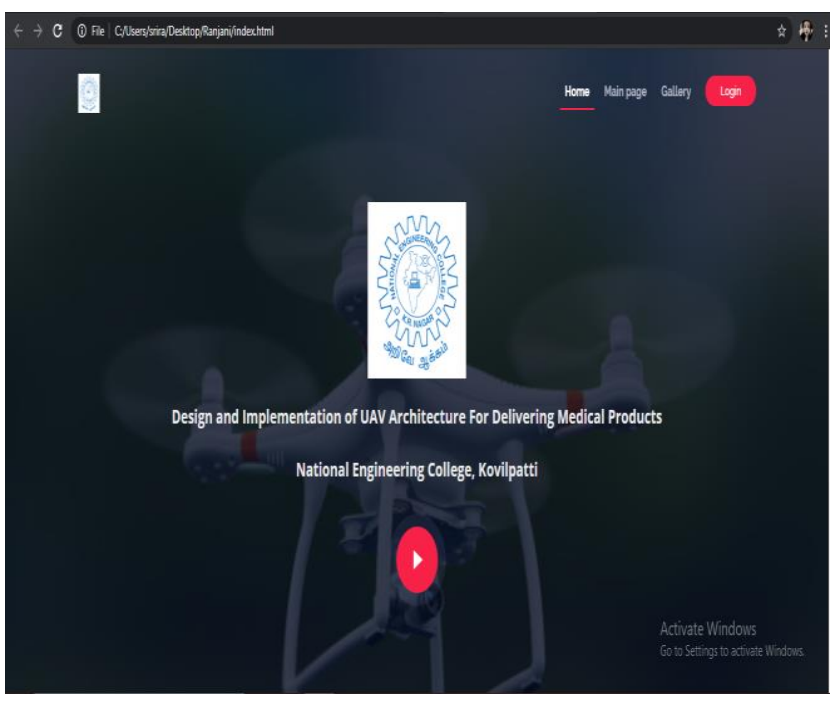

FIG 6.1 Home page of webpage

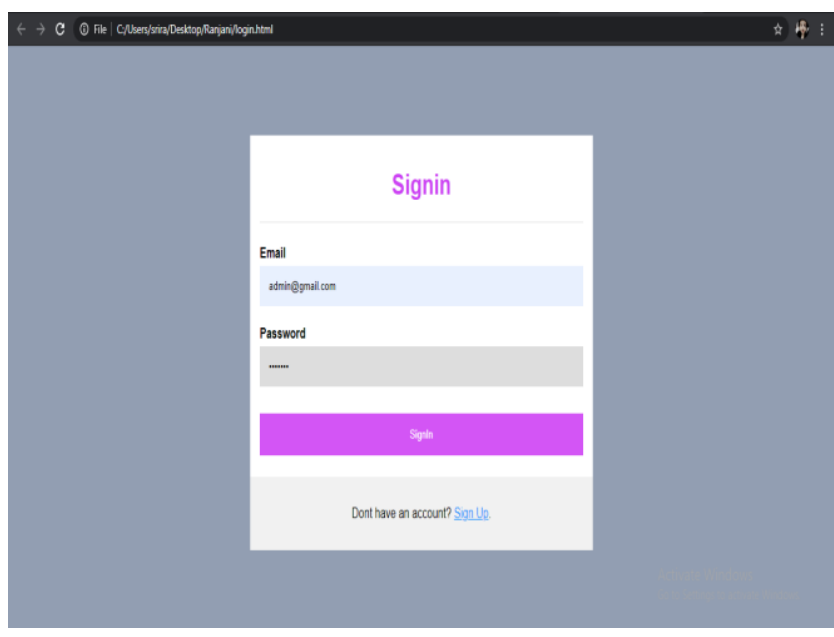

Fig 6.2 Login page of webpage

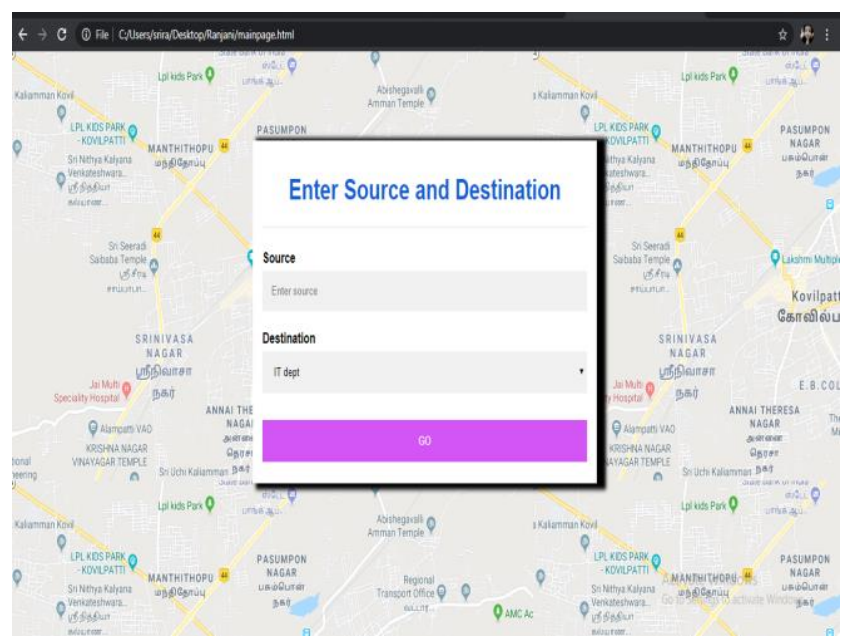

Fig 6.2 Main page of webpage

\section{VII.CONCLUSION}

Unmanned flying Vehicles have the ability to ship and convey products fastly ,securely and rapidly over the zones which are open and distant by humans. This causes them to pick up centrality in the field of ethereal conveyance and other regular citizen applications. There are such huge numbers of things which will be added to the present automaton make it work more effectively than present
drone.Future improvement to the automaton conveyance incorporates consideration of a facial distinguishing proof framework to check beneficiaries after conveyance. Additionally incorporation of OTP (Once Secret key) likewise assists with expanding the curiosity of the framework. This OTP framework encourages us to recognize that medications are conveyed to real people. Transmitter is utilized now for the control of automaton will be overhauled with auto - pilot mode with the assistance of an on-board PC program and a GPS unit. Present model is overhauled with AI system this strategy can catch increasingly nitty gritty qualities about automaton correspondences with less exertion. On investigating the consequences of the techniques, it very well may be seen that, the proposed strategy can build up a superior model which encourages us to acquire data with less exertion and less time. Moreover, the proposed strategy can be effectively reached out for the correspondence of numerous automatons. Future work will likewise incorporate the programmed route of the automaton building up an effective force supply for the UAV.

\section{REFERENCES}

1. Handwerk B (2013) 5 Surprising drone uses. A National Geographic update.

2. Australian UAV (2016) Australian UAV provides professional aerial mapping, and inspection services throughout the country using our cutting-edge drone technology.

3. Mullins N (2016) The drones of medicine. SMA, Southern Medical Blog.

4. Office for the Coordination of Humanitarian Affairs (OCHA) (2014) Policy and studies series, Unmanned aerial vehicles in humanitarian response. United Nations.

5. Thiels CA, Aho JM, Zietlow SP, Jenkins DH (2015) Use of unmanned aerial vehicles for transport Air Med J 34: 104e108.

6. R. Luppicini and A. So, "A technoethical of commercial drone use in the context of governance, ethics, and privacy," Technol. Soc., vol. 46, pp. 109-119, 2016.

7. J. Lohn, "What's the buzz? The city-scale impacts of drone delivery," RAND Corp., Santa Monica, CA, USA, RR-1718-RC, Dec. 2017

8. V. Shelley, "A model of human harm from a falling unmanned aircraft Implications for UAS regulation," Int. J. Aviation, Aeronaut., Aerosp., vol. 3, no. 3, pp. 1-42, 2016. X. Liu, J. Heo, and L. Sha, "Modeling 3-tiered Web applications," in Proc. 13th IEEE Int. Symp. Model., Anal., Simul. Comput. Telecommun. Syst., 2005, pp. 307-310.

9. F. Tang, Z. M. Fadlullah, N. Kato, F. Ono, and R. Miura, "AC-POCA Anticoordination game based partially overlapping channels assignmentin combined UAV and D2D-based networks," IEEE Trans. Veh. Technol.,vol. 67, no. 2, pp. 1672-1683, Feb. 2018.

10. M. Liu, J. Yang, and G. Gui, "DSF-NOMA: UAV-assisted emergencycommunication technology in a heterogeneous Internet of Things," IEEEInternet Things J., to be published. doi: 10.1109/JIOT.2019.2903165.

11. Z. M. Fadlullah,TakaisH. Nishiyama, N. Kato, and R. Miura A dynamic trajectory control algorithm for improving the communication throughput and delay in UAV-aided networks," IEEE Netw., vol. 30, no. 1,pp. 100-105, Jan./Feb. 2016.

12. S. Jeong, O. Simeone, and J. Kang, "Mobile edge computing via a UAV-mounted cloudlet: Optimization of bit allocation and path planning," IEEETrans. Veh. Technol., vol. 67, no. 3, pp. 2049-2063, Mar. 2018.

13. Y. Kawamoto, H. Nishiyama, N. Kato, F. Ono, and R. Miura, “Toward future unmanned aerial vehicle networks: Architecture, resource allocation and field experiments," IEEE Wireless Commun., vol. 26 no. 1, pp. 94-99 \& Tutorials, vol. 19, no. 1, pp. 57-96, 2017

14. future prospects," Remote Sensing of Environment, vol. 175, pp. 196-204, 2016. 
Design and Implementation of UAV Architecture for Delivering Medical Products

\section{AUTHORS PROFILE}

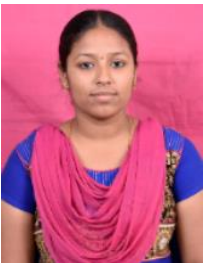

K. Nagasivaranjani, was born in Tirunelveli in 1998 was currently pursuing her Batchelor of Engineering in National Engineering College,Kovilpatti,India. She attended many technical workshops and participated in many events conducted by different college.She was a active member of IEEE. Her area of interest is Digital electronics and Electronics Circuits.she completed her mini project in the domain of Embedded systems.

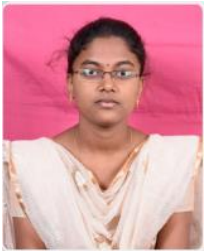

V. Muthu Kavitha, was born in Tirunelveli in 1998 was currently pursuing her Batchelor of Engineering in National Engineering College,Kovilpatti,India.She attented many workshops and conducted various events in college. She was a active member of IEEE. Her area of interest is Digital electronics and Networks.she completed her mini project in the domain of Embedded systems.

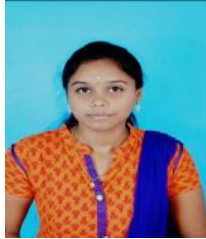

V. Divya Prabha, was born in Tutucorin in 1998 was currently pursuing her Batchelor of Engineering in National Engineering College,Kovilpatti,India. She attended many technical workshops in cyber security and networks. She was a active member of IETE club. Her area of interest is Networks and cyber security. she completed her mini project in the domain of Networks.

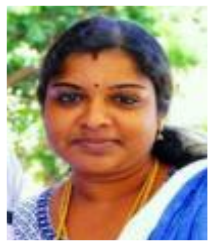

C. Asha Beaula, was born in Nagercoil, India in 1988. She received her bachelor's degree in Electronics and Communication Engineering from Anna University, Chennai, India in 2009. Then, she obtained her master's degree in Applied Electronics from Anna University, Chennai, India in 2011. In 2011, she joined in the Department of Electronics and Communication Engineering, Unnamalai institute of technology, as a Lecturer, and in 2013 became an Assistant Professor at National Engineering College till now. Her research interests include Device modelling and 5G Wireless Communication. She has presented many research papers in various conferences. She is an institutional member of IEEE, and a fellow member of Indian Society of Technical Education (ISTE), Professional member at The Society of Digital Information and Wireless Communications (SDIWC). 